J Neurosurg Spine 20:772, 2014

(C)AANS, 2014

\title{
Erratum
}

\section{Effect of machined interfacet allograft spacers on cervical foraminal height and area}

\section{Laboratory investigation}

To THE EDIToR: In our publication "Effect of machined interfacet allograft spacers on cervical foraminal height and area. Laboratory investigation" (J Neurosurg Spine 20:178-182,2014), we recently noted an error in the unit reported for foraminal area measurement. This did not affect the statistical analysis, and all other aspects of the paper are correct.

The unit used for the foraminal area should have been square centimeter instead of square millimeter, as it currently appears in the published article. In particular, we would like to make the following corrections:

1. Abstract, Results, last sentence: "The average increase in foraminal area was $18.4 \%\left(0.097 \mathrm{~mm}^{2}\right)$ " should be "The average increase in foraminal area was $18.4 \%\left(0.097 \mathbf{c m}^{2}\right)$."

2. Results section, second-to-last sentence: "The overall average increase in foraminal area was $18.39 \%\left(0.097 \mathrm{~mm}^{2}\right)$ " should be "The overall average increase in foraminal area was $18.39 \%\left(0.097 \mathbf{c m}^{2}\right) . "$

\author{
3. Table 3: "Area in $\mathrm{mm}^{2 \text { " }}$ should be changed to "Area in \\ $\mathbf{c m}^{2}$."
}

The corrections are in boldface. The corrected table appears below.

We apologize to the editor and readers for our errors, and we are pleased to have the opportunity to make these corrections. The errors were corrected online as of April 4, 2014.

LeE A. TAN, M.D. Carter S. Gerard, M.D.

Vincent C. TRaynelis, M.D. Rush University Medical Center

Chicago, IL

Paul A. Anderson, M.D.

University of Wisconsin

Madison, WI

TABLE 3: Mean foraminal area before and after interfacet allograft placement

\begin{tabular}{cccc}
\hline & \multicolumn{2}{c}{ Area in $\mathrm{cm}^{2 *}$} & \\
\cline { 2 - 3 } Level & Baseline & After Graft & Increase (\%) \\
\hline C4-5 & $0.53 \pm 0.17$ & $0.63 \pm 0.16$ & 18.48 \\
C5-6 & $0.48 \pm 0.10$ & $0.53 \pm 0.13$ & 10.56 \\
C6-7 & $0.55 \pm 0.16$ & $0.69 \pm 0.18$ & 26.12 \\
overall & $0.52 \pm 0.14$ & $0.62 \pm 0.17$ & 18.39 \\
\hline
\end{tabular}

* Mean \pm SD.
Please include this information when citing this paper: published online April 4, 2014; DOI: 10.3171/2014.3.SPINE131a. 